CLINICAL STUDY

\title{
Thyroid diseases cause mismatch between MIBI scan and neck ultrasound in the diagnosis of hyperfunctioning parathyroids: usefulness of FNA-PTH assay
}

\author{
Francesco Boi, Cira Lombardo, Maria Chiara Cocco, Mario Piga ${ }^{1}$, Alessandra Serra ${ }^{1}$, Maria Letizia Lai ${ }^{2}$, \\ Pietro Giorgio Calò ${ }^{3}$, Angelo Nicolosi ${ }^{3}$ and Stefano Mariotti \\ Endocrinology and ${ }^{1}$ Nuclear Medicine, Department of Medical Sciences 'M. Aresu', University of Cagliari and A.O.U. Presidio di Monserrato, SS 554, \\ I-09042 Monserrato-Cagliari, Italy, ${ }^{2}$ Department of Cytomorphology and ${ }^{3}$ Department of Surgery, University of Cagliari, Monserrato, Cagliari, Italy \\ (Correspondence should be addressed to F Boi; Email: francesco.boi@tin.it)
}

\begin{abstract}
Design: To evaluate the efficacy of the main tools in the diagnostic localization of hyperfunctioning parathyroids (HP) in primary hyperparathyroidism (pHPT) with concomitant thyroid diseases. Methods: Forty-three patients with pHPT associated with nodular goiter (NG, $n=32$ ) and/or autoimmune thyroid diseases (AITDs, $n=11$ ) for a total of 63 neck lesions were considered. Sixteen patients displaying HP (16 lesions), unequivocally localized by sestaMIBI scintigraphy (MIBI) and neck ultrasound (US) (group I), were compared with 27 patients (47 neck lesions) displaying equivocal parathyroid localization (group II). In all cases, neck US, MIBI scan, cytology, and parathyroid hormone assay in fine-needle aspiration washout fluid (FNA-PTH) were performed. All patients finally underwent surgery.

Results: According to histological examination, high FNA-PTH values $(>103 \mathrm{pg} / \mathrm{ml})$ correctly identified all HP in both groups of patients (100\% of sensitivity and specificity). Both MIBI and US correctly identified all HP only in group I patients; in contrast, four patterns of mismatch between these techniques were observed in group II patients, leading to low diagnostic performances of neck US (71.4\% sensitivity and $78.9 \%$ specificity) and of MIBI scan (35.7\% sensitivity and $42.1 \%$ specificity). The latter was due to both false-negative (mainly in AITD) and false-positive (mainly in NG) scan images.

Conclusions: Coexistent thyroid diseases are responsible for mismatch between MIBI and US images resulting in equivocal HP localization. In these cases, FNA-PTH resulted in the most accurate tool to identify HP. However, although safe, it should be advised only to patients with uncertain HP localization.
\end{abstract}

European Journal of Endocrinology 168 49-58

\section{Introduction}

Primary hyperparathyroidism (pHPT) is an endocrine disease mainly caused by single or multiple hyperfunctioning parathyroid (HP) lesions (adenomas, hyperplasia, or rarely carcinomas) $(1,2)$. The identification of HP is an important step to plan surgery, which represents the definitive therapeutic approach of pHPT (3). Although bilateral neck exploration (BNE) performed by an experienced surgeon may allow the intraoperative identification of HP (4), in some cases, such as in the presence of concomitant thyroid nodular disease, this approach may fail. For this reason, preoperative localization studies have been regarded as necessary but their use is still controversial (5). Some authors suggest that these studies may reduce surgical time, technical failures, complication rates (6), improving
pHPT operation by minimally invasive parathyroidectomy (MIP) $(7)$, and radioguided $(8,9)$ surgery. Several imaging techniques such as neck ultrasound (US) $(10,11)$, computerized tomography (CT) (12), and dual-phase ${ }^{99 \mathrm{~m}}$ technetium sestaMIBI (MIBI) scan associated with single-photon emission CT (SPECT)CT are currently available (13), although neck US and MIBI scan are generally used as first tools in the diagnostic approach of pHPT (14).

MIBI is a lipophilic monovalent cation showing increased uptake in epithelial cells rich in mitochondria such as HP cells $(15,16)$. MIBI scan is able to localize HP in pHPT patients with high sensitivity (71-93\%) and specificity $(90 \%)$ and, for this reason, it has been used as the technique of choice to guide MIP (17). However, small dimension of HP, oxyphil cell content, and various degree of apoptosis or necrosis may reduce 
MIBI uptake causing false-negative results (18, 19). On the other hand, MIBI retention is not parathyroid specific and is also observed in hypermetabolic thyroid nodules (TNs) such as oncocytic tumors (20) and autonomous thyroid adenomas (TA) $(20,21)$. Neck US is the least invasive and cheapest method $(11,22)$ to accurately localize HP, but its efficacy is related to the operator experience and may be reduced in the presence of concomitant nodular goiter (NG) $(23,24)$. No studies on the potential interference of autoimmune thyroid disease (AITD), such as Hashimoto's thyroiditis (HT) and Graves' disease (GD) in HP localization by MIBI scan and neck US, have been so far performed. Finally, other potential conditions leading to uncertain HP localization by these techniques are represented by ectopic parathyroid location, multiglandular HP hyperplasia, and exceptionally lymphoadenopathies (20, 24, 25).

The association between TNs with pHPT occurs frequently in iodine-deficient areas (Italy or Central Europe) where the incidence of NG varies from 20 to $60 \%$, and this has been reported to reduce the diagnostic performance of MIBI scan to $\sim 60-70 \%$. In such a condition, the combined use of MIBI scan and neck US may also improve the diagnostic efficacy, but a $15-20 \%$ of inaccurate localization $(20,26,27)$ still remains. In these last years, the assay of intact parathyroid hormone in washout fluid from fine-needle aspirate (FNA-PTH) has been proposed as a further diagnostic tool to improve the detection of $\mathrm{HP}$ in patients with NG $(28,29,30)$. However, this procedure is still a matter of controversy, mainly for the concern of subsequent technical difficulties in HP surgery (31) and potential mistakes in histological interpretation (32).
With these concepts in mind, this study was aimed to reevaluate the potential interference of the most frequent thyroid diseases (NG and AITD) on MIBI scan and neck US diagnostic accuracy and redefine the diagnostic role and value of FNA-PTH in HP localization.

\section{Materials and methods}

\section{Patients}

We conducted a retrospective cohort study based on hospital records of 43 consecutive patients (ten males and 33 females, aged 37-80 years, and mean 59 years) with diagnosis of pHPT and concomitant NG $(n=32)$ or AITD ( $n=9$ HT and $n=2 \mathrm{GD}$ ) who were referred to the out clinic service of our Endocrinology Unit during a 6-year period (2003-2008). The diagnosis of pHPT was based on elevated serum PTH along with elevated or high normal range serum calcium (see Tables 1 and 2). The diagnosis of AITD was made in the presence of positive serum antithyroid autoantibodies (ATA), typical thyroid US hypoechoic pattern, and/or primary hypo/ hyperthyroidism. The diagnosis of NG was made by neck US in the presence of increased thyroid volume and/or in the presence of single or multiple TNs. All patients were also submitted to an accurate physical examination, MIBI scan, FNA-PTH measurement, and FNA cytology of their neck masses (a total of 63 neck lesions), performed as detailed later. The results of all diagnostic procedures were retrospectively reviewed. Written informed consent was obtained from each patient after full explanation of the purpose and nature

Table 1 Clinical, biochemical, and pathological data in patients of group I: MIBI scan and neck US images fully concordant with HP localization.

\begin{tabular}{|c|c|c|c|c|c|c|c|c|c|c|c|}
\hline Patient & Age & Sex & $\begin{array}{c}\text { Serum } \\
\text { PTH }(p g / m l)\end{array}$ & $\begin{array}{c}\text { Serum Ca } \\
(\mathrm{mg} / \mathrm{dl})\end{array}$ & $\begin{array}{c}\mathbf{N G} \\
(+/-)\end{array}$ & $\begin{array}{c}\text { AITD } \\
(+/-)\end{array}$ & $\begin{array}{l}\text { US } \\
(+/-; \\
\mathrm{mm}) / \text { site }\end{array}$ & $\begin{array}{c}\text { MIBI } \\
(+/-)\end{array}$ & Cytology & $\begin{array}{c}\text { FNA-PTH } \\
(\mathrm{pg} / \mathrm{ml})\end{array}$ & Histology \\
\hline \multicolumn{12}{|l|}{ Group I } \\
\hline 1 & 57 & $\mathrm{~F}$ & 107 & 11.2 & + & - & $+12 / \mathrm{D}$ & + & Comp & 3693 & PA \\
\hline 2 & 51 & $\mathrm{~F}$ & 155 & 11.5 & + & - & $+14 / \mathrm{N}$ & + & Comp & 8673 & PA \\
\hline 3 & 58 & $\mathrm{~F}$ & 96 & 10.8 & + & - & $+20 / \mathrm{N}$ & + & Comp & 2999 & PA \\
\hline 5 & 55 & $\mathrm{M}$ & 103 & 10.9 & + & - & $+16 / \mathrm{N}$ & + & ND & $>2500$ & $\mathrm{PA}$ \\
\hline 6 & 37 & $\mathrm{M}$ & 156 & 11.8 & - & - & $+10 / \mathrm{D}$ & + & Comp & $>2500$ & PA \\
\hline 7 & 46 & $F$ & 288 & 10.8 & - & - & $+15 / \mathrm{N}$ & + & Comp & 517 & PA \\
\hline 8 & 45 & $\mathrm{~F}$ & 236 & 11.3 & + & - & $+10 / \mathrm{N}$ & + & Comp & $>2500$ & $\mathrm{PA}$ \\
\hline 9 & 51 & $\mathrm{M}$ & 155 & 10.5 & - & - & $+10 / l$ & + & ND & 1215 & PA \\
\hline 10 & 74 & $\mathrm{~F}$ & 461 & 12.2 & + & - & $+20 / \mathrm{N}$ & + & Comp & $>2500$ & $\mathrm{PA}$ \\
\hline 11 & 63 & $\mathrm{~F}$ & 90 & 10.8 & - & - & $+12 / \mathrm{N}$ & + & Foll & $>2500$ & PA \\
\hline 12 & 62 & $\mathrm{~F}$ & 1367 & 14.1 & - & - & $+11 / D$ & + & ND & $>2500$ & PA \\
\hline 14 & 69 & $\mathrm{M}$ & 407 & 13.34 & + & - & $+19 / \mathrm{N}$ & + & ND & 989 & PA \\
\hline 15 & 80 & $\mathrm{~F}$ & 335 & 10.9 & + & $+(\mathrm{GD})$ & $+10 / D$ & + & Comp & $>5000$ & $\mathrm{PH}$ \\
\hline 16 & 52 & $\mathrm{M}$ & 110 & 11.3 & + & - & $+6 / I$ & + & Foll & 643 & $\mathrm{PA}$ \\
\hline
\end{tabular}

Sex: F, female; M, male; neck US and MIBI scan (+, positive; -, negative for HP); HP site: D, distant; N, near; and I, inside the thyroid. NG and AITD (+, presence; -, absence); cytology: comp, compatible with HP; foll, follicular pattern; ND, not diagnostic. Histology of hyperfunctioning parathyroids: $\mathrm{PA}$, parathyroid adenoma; $\mathrm{PH}$, parathyroid hyperplasia. 
Table 2 Clinical, biochemical, and pathological data in patients of group II: group II-A, patients with negative MIBI scan; group II-B, patients with MIBI uptake projected on a neck nodule not corresponding to HP; group II-C, patients with a double focus of MIBI uptake; and group II-D, patients with MIBI focus projected in a neck area where two adjacent lesions were present.

\begin{tabular}{|c|c|c|c|c|c|c|c|c|c|c|c|}
\hline Patient & Age & Sex & $\begin{array}{c}\text { Serum } \\
\text { PTH } \\
\text { (pg/ml) }\end{array}$ & $\begin{array}{c}\text { Serum } \\
\text { Ca } \\
(\mathrm{mg} / \mathrm{dl})\end{array}$ & $\begin{array}{c}\mathbf{N G} \\
(+/-)\end{array}$ & $\begin{array}{c}\text { AITD } \\
(+/-)\end{array}$ & $\begin{array}{l}\text { US }(+/- \text {; } \\
\mathrm{mm}) / \text { site }\end{array}$ & $\begin{array}{c}\text { MIBI } \\
(+/-)\end{array}$ & Cytology & $\begin{array}{l}\text { FNA- } \\
\text { PTH } \\
(\mathrm{pg} / \mathrm{ml})\end{array}$ & Histology \\
\hline \multicolumn{12}{|c|}{ Group II-A } \\
\hline 1 & 60 & M & 140 & 12.07 & - & $+(\mathrm{HT})$ & $+20 / D$ & - & Comp & $>2500$ & PC \\
\hline 2 & 57 & $\mathrm{M}$ & 110 & 13.35 & + & - & $+25 / \mathrm{N}$ & - & Foll & $>2500$ & PA \\
\hline 3 & 68 & $\mathrm{~F}$ & 121 & 10.3 & + & - & $+5 / \mathrm{N}$ & - & Comp & $>2500$ & PA \\
\hline 4 & 68 & $\mathrm{~F}$ & 392 & 15.06 & + & - & $+35 / \mathrm{D}$ & - & ND & $>2500$ & PA (cystic) \\
\hline 5 & 58 & $\mathrm{~F}$ & 225 & 11.05 & - & $+(\mathrm{HT})$ & $+11 / \mathrm{N}$ & - & Comp & 830 & PA \\
\hline 6 & 37 & $\mathrm{~F}$ & 107 & 9.07 & + & $+(\mathrm{HT})$ & $+15 / \mathrm{N}$ & - & ND & 366 & PA \\
\hline 7 & 57 & M & 99 & 11 & - & $+(\mathrm{GD})$ & $+14 / \mathrm{N}$ & - & Foll & $>2500$ & PA \\
\hline $8 \mathrm{~A}$ & 64 & $\mathrm{~F}$ & 222 & 11.2 & + & - & $-14 / D$ & - & Comp & $>2500$ & PA \\
\hline $8 B$ & 64 & $\mathrm{~F}$ & 222 & 11.2 & + & - & -10 & - & Foll & 4.4 & PTC \\
\hline $9 \mathrm{~A}$ & 63 & $\mathrm{~F}$ & 113 & 10.8 & + & $+(\mathrm{HT})$ & $-8 / 1$ & - & ND & $>2500$ & PA \\
\hline $9 \mathrm{~B}$ & 63 & $\mathrm{~F}$ & 113 & 10.8 & + & $+(\mathrm{HT})$ & -25 & - & Foll & 6 & TA \\
\hline $10 \mathrm{~A}$ & 53 & $\mathrm{~F}$ & 119 & 12 & + & $+(\mathrm{HT})$ & $-9 / 1$ & - & Comp & $>2500$ & $\mathrm{PH}$ \\
\hline $10 \mathrm{~B}$ & 53 & $\mathrm{~F}$ & 119 & 12 & + & $+(\mathrm{HT})$ & -15 & - & Foll & 16 & HTN \\
\hline \multicolumn{12}{|c|}{ Group II-B } \\
\hline $1 \mathrm{~A}$ & 62 & $\mathrm{~F}$ & 157 & 11.5 & + & - & $+15 / \mathrm{N}$ & - & Comp & 741 & PA \\
\hline 1B & 62 & $\mathrm{~F}$ & 157 & 11.5 & + & - & -10 & + & Foll & $<3$ & HTN \\
\hline $2 A$ & 60 & $M$ & 128 & 10.5 & + & - & $+14 / D$ & - & Comp & $>2500$ & $\mathrm{PA}$ \\
\hline $2 \mathrm{~B}$ & 60 & M & 128 & 10.5 & + & - & -12 & + & ND & 34.3 & Lymphoma \\
\hline $3 A$ & 60 & $\mathrm{~F}$ & 200 & 12 & + & $+(\mathrm{HT})$ & $+27 / I$ & - & Foll & $>2500$ & $\mathrm{PH}$ \\
\hline 3B & 60 & $\mathrm{~F}$ & 200 & 12 & + & $+(\mathrm{HT})$ & -38 & + & Foll & 12.4 & TA (toxic) \\
\hline $4 \mathrm{~A}$ & 79 & $\mathrm{~F}$ & 294 & 10.02 & + & $+(\mathrm{HT})$ & -22 & + & Foll & 29.6 & FC (oncocytic) \\
\hline 4B & 79 & $\mathrm{~F}$ & 294 & 10.02 & + & $+(\mathrm{HT})$ & -22 & + & Foll & 22.2 & HTN \\
\hline $4 \mathrm{C}$ & 79 & F & 294 & 10.02 & + & $+(\mathrm{HT})$ & $+10 / D$ & - & ND & $>2500$ & PA \\
\hline \multicolumn{12}{|c|}{ Group II-C } \\
\hline $1 \mathrm{~A}$ & 74 & $\mathrm{~F}$ & 362 & 10.02 & + & - & $+18 / \mathrm{N}$ & + & Foll & 366 & PA \\
\hline 1B & 74 & $\mathrm{~F}$ & 362 & 10.02 & + & - & $-15 / \mathrm{N}$ & + & Comp & $>2500$ & PA \\
\hline $2 A$ & 62 & $\mathrm{~F}$ & 344 & 12.3 & + & - & $+17 / \mathrm{N}$ & + & Foll & 2571 & PA \\
\hline $2 B$ & 62 & $\mathrm{~F}$ & 344 & 12.3 & + & - & -20 & + & Foll & 6 & PTC \\
\hline $3 \mathrm{~A}$ & 63 & $\mathrm{~F}$ & 107 & 10.6 & + & - & $+23 / D$ & + & Comp & $>2500$ & $\mathrm{PA}$ \\
\hline $3 B$ & 63 & $\mathrm{~F}$ & 107 & 10.6 & + & - & -21 & + & Foll & 5.9 & PTC \\
\hline $4 \mathrm{~A}$ & 74 & $\mathrm{~F}$ & 152 & 11.36 & + & - & $+14 / D$ & + & Comp & $>2500$ & PA \\
\hline 4B & 74 & $\mathrm{~F}$ & 152 & 11.36 & + & - & -22 & + & NA & NA & Lung cancer \\
\hline \multicolumn{12}{|c|}{ Group II-D } \\
\hline $1 \mathrm{~A}$ & 59 & $\mathrm{~F}$ & 111 & 11.8 & + & - & -16 & + & Foll & $<3$ & HTN \\
\hline 1B & 59 & $\mathrm{~F}$ & 111 & 11.8 & + & - & $-20 / N$ & + & Foll & $>2500$ & PA \\
\hline $2 A$ & 60 & $\mathrm{~F}$ & 221 & 11 & + & - & $+10 / D$ & + & ND & $>2500$ & $P A$ \\
\hline $2 B$ & 60 & $\mathrm{~F}$ & 221 & 11 & + & - & -15 & + & ND & 15.5 & TA \\
\hline $3 A$ & 56 & $\mathrm{~F}$ & 1365 & 13 & + & $+(\mathrm{HT})$ & -8 & + & Foll & $<3$ & HTN \\
\hline 3B & 56 & $\mathrm{~F}$ & 1365 & 13 & + & $+(\mathrm{HT})$ & $+25 / D$ & + & Comp & $>2500$ & PA \\
\hline $4 \mathrm{~A}$ & 56 & $\mathrm{~F}$ & 244 & 10.52 & + & - & -15 & + & ND & 19.01 & HTN \\
\hline $4 B$ & 56 & $\mathrm{~F}$ & 244 & 10.52 & + & - & $-15 / \mathrm{N}$ & + & Comp & 2332 & PA \\
\hline $5 \mathrm{~A}$ & 64 & $\mathrm{~F}$ & 178 & 10.99 & + & - & $+20 / \mathrm{D}$ & + & Comp & $>2500$ & PA \\
\hline $5 B$ & 64 & $\mathrm{~F}$ & 178 & 10.99 & + & - & -9 & + & Foll & $<3$ & PTC \\
\hline $6 \mathrm{~A}$ & 51 & $\mathrm{~F}$ & 180 & 11.6 & + & - & $-7 / 1$ & + & Foll & $>2500$ & PA \\
\hline $6 B$ & 51 & $\mathrm{~F}$ & 180 & 11.6 & + & - & -13 & + & ND & 3.07 & HTN \\
\hline $7 \mathrm{~A}$ & 65 & $\mathrm{~F}$ & 147 & 10.6 & + & - & $-13 / N$ & + & ND & $>2500$ & PA \\
\hline 7B & 65 & $\mathrm{~F}$ & 147 & 10.6 & + & - & -9 & + & Foll & 33.6 & TA (oncocytic) \\
\hline $8 \mathrm{~A}$ & 65 & $\mathrm{~F}$ & 95 & 12.4 & + & - & -24 & + & ND & $<3$ & PTC (oncocytic) \\
\hline 8B & 65 & $\mathrm{~F}$ & 95 & 12.4 & + & - & $+11 / \mathrm{D}$ & + & Comp & $>2500$ & PA \\
\hline $9 A$ & 42 & $M$ & 381 & 12.6 & + & $+(\mathrm{HT})$ & -8 & + & Foll & 4.4 & PTC \\
\hline $9 \mathrm{~B}$ & 42 & M & 381 & 12.6 & + & $+(\mathrm{HT})$ & $+20 / D$ & + & Comp & $>2500$ & PA \\
\hline
\end{tabular}

Sex: F, female; M, male; neck US and MIBI scan (+, positive, -, negative for HP); HP site: D, distant; N, near; and I, inside the thyroid. NG and AITD (+, presence; -, absence); cytology: comp, compatible with HP; foll, follicular pattern; ND, not diagnostic; NA, not available. Histology of hyperfunctioning parathyroids: PA, parathyroid adenoma; PH, parathyroid hyperplasia; PC, parathyroid carcinoma. Histology of thyroid nodules: HTN, hyperplastic thyroid nodule; TA, thyroid adenoma; PTC, papillary thyroid carcinoma. 
of all procedures used. The Institutional Review Board of University Hospital of Cagliari reviewed and approved the protocol of this study.

The choice of the surgical approach of pHPT was based on the results of all the diagnostic procedures employed to localize HP and on the basis of associated significant thyroid diseases, which may need surgical treatment. As detailed in the Results section, when patients obtained a satisfactory localization of their HP, a MIP was performed; in those with more than one suspicious HP or concomitant significant thyroid diseases, a BNE was preferred. Furthermore, in all cases, confirmation of radical pHPT treatment was reached either by the demonstration of intraoperative significant reduction of serum PTH and/or by persistent normalization of serum calcium levels.

\section{Hormonal assays}

Serum-free thyroxine $\left(\mathrm{FT}_{4}\right)$, free tri-iodothyronine $\left(\mathrm{FT}_{3}\right)$, and TSH were assayed by automatic ultrasensitive chemiluminescent assay (Ortho Clinical Diagnostic SpA, Milan, Italy). Anti-thyroperoxidase (TPOAb), anti-thyroglobulin $(\mathrm{TgAb})$ autoantibodies, and PTH (in serum and in FNAB fluid) were measured by chemiluminescent assay: Immulite 2000 (Diagnostic Products Corporation, Los Angeles, CA, USA; distributor Medical Systems Corporation, Genoa, Italy) and anti-TSH receptor autoantibodies (TRAbs) by radioreceptor assay (TRAKhuman, BRAHMS, Hennigsdorf, Germany; distributor DASIT SpA, Milan, Italy). By these procedures, normal range values were as follows: $\mathrm{FT}_{4} 7.7-21.9 \mathrm{pg} / \mathrm{ml}, \mathrm{FT}_{3} 2.77-5.27 \mathrm{pg} / \mathrm{ml}$, TSH $0.2-$ $3.0 \mu \mathrm{U} / \mathrm{ml}$, TPOAb $<35 \mathrm{IU} / \mathrm{ml}, \mathrm{TgAb}<40 \mathrm{IU} / \mathrm{ml}$, $\mathrm{TRAb}<1.0 \mathrm{U} / \mathrm{ml}$, and serum PTH $1-87 \mathrm{pg} / \mathrm{ml}$. For FNA-PTH, see the paragraph related to the cutoff values. Patients with increased ATA titers were considered ATA positive.

\section{US with color flow doppler sonography}

US and color flow doppler sonography (CFDS) of the neck were performed by one of the authors (F Boi) using a Sonoline G60S (Siemens, Medical Solutions, Issaquah, WA, USA) color Doppler system with a $8-13 \mathrm{mHz}$ linear electronic transducer. The examiner was unaware of any prior imaging results using other techniques. The examination (conventional gray-scale US, followed by CFDS) included the central neck from the subclavian vein to the submandibular glands. The images were obtained with hyperextended position and lateral rotation of the neck to better visualize the common parathyroid ectopic sites (paraesophageal, paravertebral regions, within the thyroid gland, etc.). Enlarged parathyroid glands typically appear as an oval or triangular mass with sharp borders, homogenous hypoechoic texture with hypervascularization at CFDS. Usually, HP were found lying posterior and adjacent to the upper one-third of the thyroid lobes or adjacent to the lower pole. All neck masses were localized and their diameters were measured by US. The position of HP with respect to the thyroid gland was defined as follows: near to or inside the thyroid when HP were strictly adjacent or embedded in the thyroid, and distant when HP resulted clearly separated from thyroid lobes. US and CFDS standard criteria (20) were also employed to evaluate and select concomitant TNs to be submitted to FNA.

\section{Parathyroid ${ }^{99 m}$ Tc-MIBI scintigraphy}

The patients received $400 \mathrm{MBq}{ }^{99 \mathrm{~m}} \mathrm{Tc}-\mathrm{MIBI}$ (Cardiolite, Bristol-Meyers-Squibb, Brussels, Belgium) by i.v. injection. Anterior planar images of the neck and chest were obtained immediately after the injection (thyroid phase) and at 30 and $60 \mathrm{~min}$ later (parathyroid phase), each for $10 \mathrm{~min}$, using a dual-head gamma camera (Varicam, General Electric Medical System, Milwaukee, WI, USA) equipped with high-resolution low-energy parallel-hole collimators. SPECT images of the same area were obtained after study of parathyroid phase with 120 frames at $25 \mathrm{~s} /$ frame and $3^{\circ}$ angles over a $360^{\circ}$ arc. The images were acquired into a $128 \times 128$ matrix and reconstructed using Hanning filter. Thyroid scan was performed the following day with the same gamma camera. Anterior planar images were acquired $20 \mathrm{~min}$ after an i.v. injection of $4 \mathrm{mCi}(152 \mathrm{MBq})$ of ${ }^{99 \mathrm{~m}}$ Tc-pertechnetate. Visual analysis of the thyroid and MIBI scan were interpreted by experienced nuclear medicine physicians (M Piga and A Serra) who were unaware of US results. Patients were studied with standard MIBI scan integrated with SPECT/CT study to better evaluate the correspondence with neck US images. The MIBI scan was considered positive in locating abnormal parathyroid when one or more areas of increased and persistent MIBI uptake were detected in early and/or late acquisition and mismatched on ${ }^{99} \mathrm{~m} \mathrm{TcO} 4$ uptake revealed by previous thyroid scan.

\section{FNA cytology and FNA-PTH}

Written informed consent was obtained before US-guided FNA, which was performed using 22-25 gauge needles attached to a $10 \mathrm{ml}$ syringe. One or no more than two passes were performed on each neck lesion. FNA cytology and histology were performed by an experienced pathologist (M L Lai), who was unaware of neck US and MIBI images. Cytological diagnosis of TNs and HP was expressed according to standard criteria $(20,33)$. For the purpose of this study, FNA cytology was considered 'positive' when suggestive of HP and 'negative' in the absence of HP features or inadequate sample. After smear preparation, the needle was washed out with $500 \mu \mathrm{l}$ PTH-free serum dilution buffer and the solution processed for PTH measurement. Histological diagnosis on surgical specimens of HP and 
TNs was made using standard criteria and appropriate pathological techniques $(20,33,34)$.

\section{Cutoff values for FNA-PTH}

To correctly interpret the results of hormonal assays in FNA, we had to establish a cutoff above which FNA-PTH concentrations in washout fluid could be considered expression of local hormonal production, rather than the result of peripheral blood contamination. For this purpose, we retrospectively compared all hormonal FNA results from HP and not-HP of this series. On the basis of this analysis, all FNA-PTHs more than three times $(103 \mathrm{pg} / \mathrm{ml})$ the maximal concentration found in not-HP lesions $(34.3 \mathrm{pg} / \mathrm{ml})$ were considered positive and diagnostic for HP.

\section{Statistical analysis}

The sensitivity and specificity of the different tools to correctly detect HP were evaluated using Galen \& Gambino formula (35). The potential association between AITD and NG with the presence/absence of MIBI uptake was evaluated using nonparametric test $\left(\chi^{2}\right.$ and exact Fisher's test, with 0.05 as the significance level) by Graphpad Prizm ${ }^{\circledR}$ (Graphpad Software Co., San Diego, CA, USA).

\section{Results}

\section{Performance of the diagnostic tools in HP Iocalization}

Morphological (US) and functional (MIBI scan) images allowed the precise localization of HP in 16 patients (indicated as group I), which were confirmed by histology. In the remaining 27 patients (included in group II), US and MIBI images were discordant and identified 47 neck lesions displaying some features of HP, but, due to the presence of several degrees of mismatch, not allowing unequivocal identification of pathological parathyroids.

The complete results obtained in group I patients are detailed in Table 1. All patients of this group showed a small goiter or a single small TN $(<1 \mathrm{~cm})$ both detected by neck US.

In this group, US and MIBI images were fully concordant, allowing, in each patient, the precise identification of a single well-distinct lesion, strongly suggestive of HP. Moreover, all these MIBI-positive lesions showed high FNA-PTH concentrations $(517->2500 \mathrm{pg} / \mathrm{ml})$, resulting in all cases pathological HP (15 parathyroid adenomas (PAs) and one parathyroid hyperplasia $(\mathrm{PH})$ ) at histology. FNA cytology was positive only in 9/16 (56.2\%) of cases.

In group II patients, palpation and neck US displayed a larger goiter and/or multiple TNs. In this group, we were able to identify at least four different patterns of mismatch (described as subgroups A, B, C and D) of these procedures. All the results obtained in this group are detailed in Table 2.

In all patients of group II-A $(n=10)$, MIBI uptake was always absent (Fig. 1a) and HP was suspected by neck US (Fig. 1b) in seven of ten. These seven lesions displayed very high FNA-PTH concentrations (366-> $2500 \mathrm{pg} / \mathrm{ml}$ ) and were confirmed HP at histology (six PA and one parathyroid carcinoma (PC)). Each of the remaining three patients displayed at US two neck lesions with a echographic pattern insufficient for a clear identification of parathyroid tissue. High FNA-PTH values $(>2500 \mathrm{pg} / \mathrm{ml})$ were found only in one lesion of each patient, which was confirmed HP (two PA and one $\mathrm{PH})$ at histology. The other three lesions with low FNAPTH concentrations $(4.4-16 \mathrm{pg} / \mathrm{ml})$ resulted in thyroid origin (one TA and one papillary thyroid carcinoma (PTC), and one hyperplasic TN (HTN)) at histology.

Each patient of group II-B $(n=4)$ exhibited one or more MIBI-positive areas projected on neck nodule
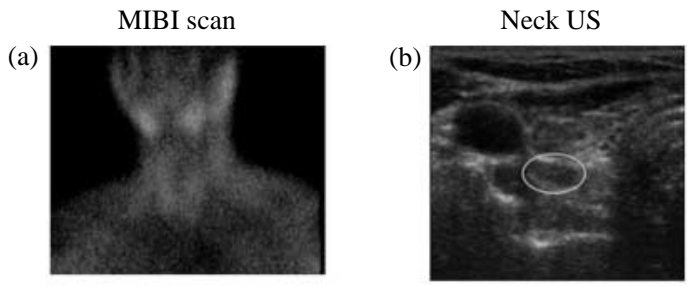

(c)
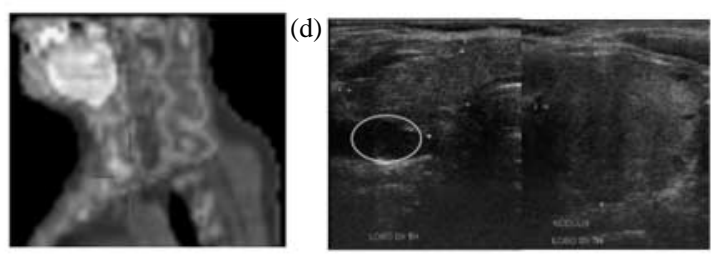

(e)
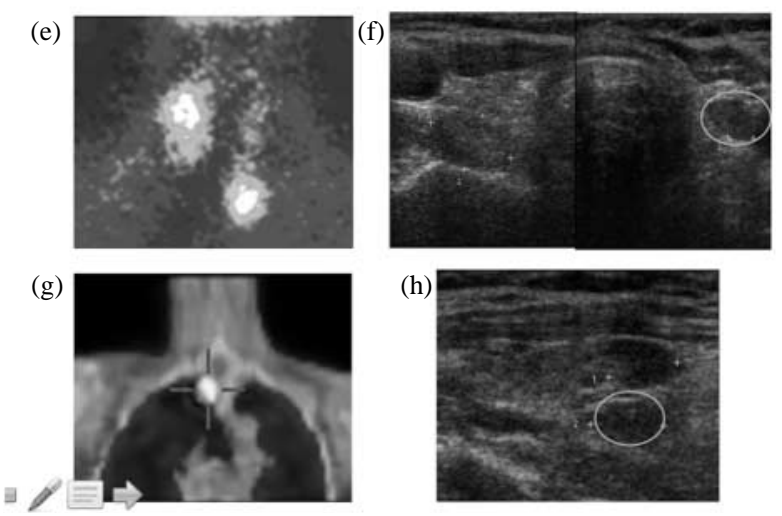

Figure 1 Selected MIBI scan and neck US images of group II patients: (a) negative MIBI scan and (b) HP detected by neck US (circled) in a patient of group II-A. (c) MIBI uptake projected on a toxic TA and (d) MIBI-negative HP detected by neck US (circled) in a patient of group II-B. (e) Double focus of MIBI uptake (projected on a PTC and on a HP) and (f) HP at neck US (circled) in a patient of group II-C. (g) Single MIBI focus projected on two adjacent neck lesions (a HTN and a HP) and (h) HP at neck US (circled) in a patient of group II-D. 


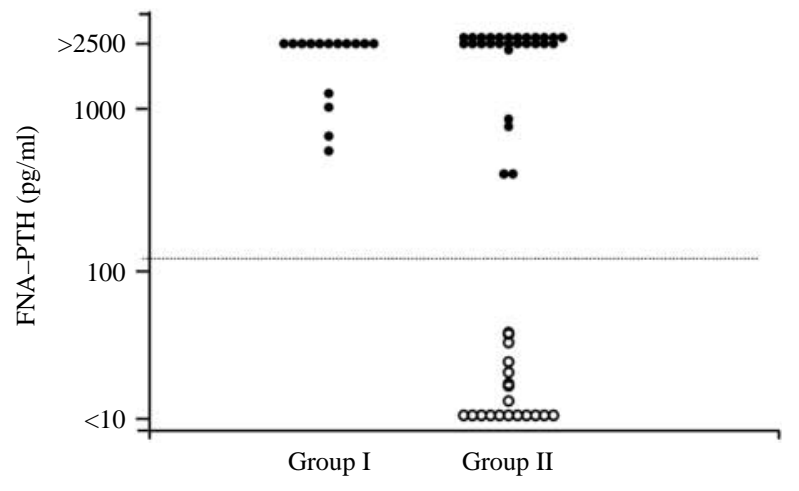

Figure 2 FNA-PTH concentrations found in histologically proven HP (filled circle) and in thyroid or other miscellaneous neck lesions (open circle). The dotted line indicates the cutoff for positive FNAPTH $(103 \mathrm{pg} / \mathrm{ml})$.

(Fig. 1c) without US features of HP, while an other neck lesion suggestive of HP at US (Fig. 1d) did not show any MIBI uptake. All four MIBI-negative neck lesions identified by US had high FNA-PTH values (741-> $2500 \mathrm{pg} / \mathrm{ml}$ ) and all resulted HP at histology (three PA and one PH). All five MIBI-positive masses (a single lesion from three patients and a double mass from one case) showing low levels of FNA-PTH $(<3-34.3 \mathrm{pg} / \mathrm{ml})$ resulted in thyroid lesion (two HTNs, one hyperfunctioning TA, and one oncocytic variant of follicular carcinoma (FC)) with exception of patient \#2 who had a local recurrence of neck lymphoma at histology.

Each patient of group II-C $(n=4)$ had two distinct and separate MIBI-positive areas; in three patients, MIBI focuses were projected in the lower third of the neck, and in the remaining case, one focus was projected in the jugular area and the other in the hilum of the left lung. Of these seven neck MIBI-positive lesions, 4/7 results were suggestive of HP at US examination and were confirmed HP at histology. High FNA-PTH $(366->2500 \mathrm{pg} / \mathrm{ml})$ was found in a total of $5 / 7$ neck lesions, all HP at histology (patient \#1 had double PA and three patients had a single PA). In two patients (\#2 and \#3), the other neck MIBI-positive focus showed low FNA-PTH (5.9-6 pg/ml) and in both cases resulted PTC at histology: one of these cases (patient \#2), a rare association between MIBI-positive PA and PTC (Fig. 1e and f), has been previously reported (26). In patient \#4, the other MIBI-positive area, located in the lung, resulted in a recurrence of lung neoplasia.

In each patient of group II-D $(n=9)$, a single MIBI focus was projected in a neck area where two similar, hypoechoic adjacent masses (Fig. $1 \mathrm{~g}$ and $\mathrm{h}$ ) were found at US. Of these 18 neck lesions, five results were suggestive of HP at US examination and were confirmed HP at histology. High FNA-PTH $(2332->2500$ pg/ml) was found in a total of 9/18 lesions, all resulting HP at histology (nine PA). All the other nine lesions with low FNA-PTH $(<3-33.6 \mathrm{pg} / \mathrm{ml})$ resulted thyroid neoplasias ((four HTNs, two TAs (one classic and one oncocytic variant), and three PTC (two classic and one oncocytic variant)) at histology.

The accuracy of all diagnostic procedures (MIBI scan, neck US, FNA-PTH, and FNA cytology) was calculated according to the Galen \& Gambino formula (35). For this purpose, MIBI uptake was considered true positive when the mass was confirmed HP at histology, false positive when the lesion resulted not-HP (i.e. TN), true negative when the mass was confirmed not-HP, and false negative when HP resulted MIBI negative. For neck US, it was considered true positive when the mass suggestive of HP was confirmed at histology, false positive when the suspected lesion resulted in notparathyroid origin, true negative when US correctly identified the other neck masses, and false negative when US failed to identify HP. For FNA-PTH, true positive was considered a value $>103 \mathrm{pg} / \mathrm{ml}$ found in histologically proven HP and true negative was considered all values $<103 \mathrm{pg} / \mathrm{ml}$ found in lesions of not-parathyroid origin. FNA cytology was considered true positive when the neck mass corresponded to HP at histology and false negative when cytology results were inadequate or not indicative of HP in histologically proven parathyroid lesions. In group I patients (Table 1), almost all techniques (MIBI scan, neck US, and FNA-PTH) allowed the correct identification of all HP, reaching $100 \%$ sensitivity, while FNA cytology resulted in only $56.2 \%$ sensitivity.

As shown in Fig. 2 and Table 3, in the whole series of group II patients, all neck masses with positive FNA-PTH values $(366->2500 \mathrm{pg} / \mathrm{ml})$ resulted HP at histology, while low FNA-PTH concentrations $(<3-33.6 \mathrm{pg} / \mathrm{ml})$ were only found in not-HP lesions. MIBI scan was true positive only in 10/28 (35.7\%) of HP lesions, while resulted false positive in 11/19 $(57.9 \%)$ neck masses of not parathyroid origin. Neck US was able to immediately identify HP in 20/28 $(71.4 \%)$ of cases and excluding a parathyroid origin in $15 / 19(78.9 \%)$ of not parathyroid lesions. FNA cytology correctly identified 15/28 (53.6\%) of HP, resulting not indicative for HP (follicular pattern) in $7 / 28$ (33.3\%)

Table 3 Comparison between MIBI scan, neck US, FNA-PTH, and FNA cytology vs histology of group II patients.

\begin{tabular}{llcc}
\hline Diagnostic tools & Results & HP $(n=28)$ & Not-HP $(n=19)$ \\
\hline MIBI scan & Positive & 10 & 11 \\
Neck US & Negative & 18 & 8 \\
& Positive & 21 & 4 \\
FNA-PTH & Negative & 7 & 15 \\
& Positive & 28 & 0 \\
FNA cytology & Negative & 0 & 19 \\
& Positive & 15 & 0 \\
& Negative & 13 & 19 \\
\hline
\end{tabular}

$\mathrm{HP}$, hyperfunctioning parathyroid at histology; not-HP, lesions different from HP at histology. MIBI scan pos, positive MIBI uptake; MIBI scan neg, absent MIBI uptake. Neck US pos, identification; neck US neg, not identification of HP by ultrasound. FNA-PTH pos, FNA-PTH greater than the cutoff; FNA-PTH neg, FNA-PTH lower than cutoff. FNA cytology pos, compatible with HP; FNA cytology neg, inadequate or not compatible with HP. 


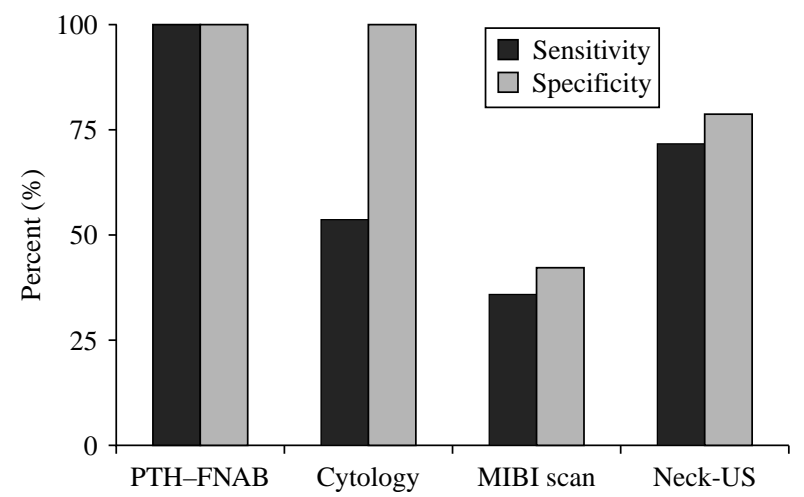

Figure 3 Sensitivity (black bar) and specificity (gray bar) of MIBI scan, neck US, FNA-PTH, and FNA cytology in the identification and localization of HP in group II patients.

and inadequate in 6/28 (21.4\%). In summary, as displayed in Fig. 3, in group II patients, FNA-PTH resulted in the best procedure able to identify all HP reaching $100 \%$ sensitivity and specificity; neck US reached $71.4 \%$ sensitivity and $78.9 \%$ specificity; MIBI scan $35.7 \%$ sensitivity and $42.1 \%$ specificity; and FNA cytology $53.6 \%$ sensitivity and $100 \%$ specificity.

Thanks to the above procedures, in patients with a fully satisfactory localization of HP (all 16 patients of group I) and in several cases with significant thyroid or other diseases (the first eight cases of group II-A, the patient with associated recurrence of neck lymphoma (group II-B), the case with mediastinum recurrence of lung neoplasia (group II-C) and four patients (\#3, \#5, \#7, and \#9) with small thyroid tumors of group II-D) who displayed an unequivocal identification of HP by FNA-PTH assay (a total of 14 of $27,52 \%$ of patients of group II), an adequate MIP (unilateral neck exploration) was performed. The remaining patients (13 of 27, $48 \%$ of patients of group II) who exhibited more than one suspicious HP or a large NG/thyroid tumors, which required an extensive surgical treatment, were submitted to a BNE.

Finally, in the postoperative 6-month follow-up, almost all $(39 / 40,97.5 \%)$ patients with histological diagnosis of PA reached radical pHPT treatment, while only one case displayed recurrence of pHPT. On the other hand, one of the three patients with $\mathrm{PH}$ and the patient with PC showed persistence of pHPT.

\section{Thyroid diseases and HP localization: effect of thyroid autoimmunity on MIBI scan}

When the results obtained with MIBI scan in group II patients were analyzed according to the nature of associated thyroid disorders, a significant increase of false-negative MIBI scans were found in the ten patients with AITD $(8 / 10,80 \%)$ when compared with patients with NG $(6 / 17,35.3 \% ; P<0.05)$. In contrast, no falsepositive MIBI scans were found in patients with associated AITD. Almost all (10/12, 83.3\%) cases of false-positive MIBI uptake were caused by TNs. In particular, between the five thyroid carcinomas, two were an oncocytic variant of FC and PTC and the remaining were three cases of classic variant of PTC; between the five benign lesions, there were three TA (one oncocytic variant, one hyperfunctioning, and one classic variant) and the remaining were two HTNs. The other two false-positive MIBI scans were represented by a neck lymphoma and a recurrence of lung neoplasia.

On the whole, as displayed in Tables 1 and 2, FNA cytology allowed the correct identification of seven concomitant malignant thyroid tumors $(n=6$ PTC, $n=1 \mathrm{FC})$ and 11 benign thyroid lesions $(n=3 \mathrm{TA}$ and $n=8$ HTNs) associated with HP, which needed to be removed in the same surgical time.

\section{Discussion}

Neck US and MIBI scan represent the first diagnostic tools to correctly plan surgery of HP (10) in the absence of concomitant cervical masses (14). False-negative neck US results may be rarely found in cases with small and ectopic HP, intrathyroidal HP, and underscent HP situated along the common carotid artery or recurrent laryngeal nerve, while false-negative MIBI scans have been observed in the presence of small size, low oxyphil cell content, and morphological changes (cystic degeneration, apoptosis, or necrosis) of HP $(18,19)$. On the other hand, difficulty in neck US and MIBI scan interpretation has been described in the presence of TNs $(20,26,36)$ with high rate of false-positive images (15-20\%) for both techniques $(24,37)$; blood vessels, esophagus, longus colli muscle, and enlarged lymph nodes (37) may represent other rare sources of falsepositive results. In contrast with nodular thyroid diseases, no studies on the potential interference of concomitant AITD in the diagnostic approach of pHPT by MIBI scan and neck US have been so far performed. Despite the usefulness of FNA-PTH in cases with inconclusive neck US and MIBI scan results, some authors reported (31) that FNA technique may be responsible for HP damage leading to fibrosis, with potential incomplete removal of HP, increased risk of laryngeal nerve injury, and the induction of false worrisome histology, which can be mistaken for carcinoma (32). These authors concluded that the routine use of this technique is unnecessary and should be avoided. This topic is still a matter of controversy, as Abraham et al. (38) rebutted that the above complications were caused by the use of large-bore needles and excessive number of FNA passes performed by operators of unknown skill levels.

With the above issue in mind, to reevaluate the real impact of the main thyroid diseases and to redefine the diagnostic role of FNA-PTH in HP diagnostic evaluation, all data from $\mathrm{pHPT}$ patients with coexistent NG 
or AITD were retrospectively compared. We found that, in the presence of concomitant large NG and/or HT (group II patients), MIBI scan and neck US images were discordant, resulting in an uncertain HP localization with four well-defined different patterns of mismatch between these techniques. In keeping with a recent study (39), coexistent NG was responsible for low diagnostic accuracy (sensitivity of $35.7 \%$ and specificity of $42.1 \%$ ) of MIBI scan and unsatisfactory diagnostic performance $(71.4 \%$ sensitivity and $78.9 \%$ specificity) of neck US. On the other hand, in the presence of concomitant small NG and absence of HT (group I patients), both neck US and MIBI scan displayed an excellent diagnostic performance in HP detection. Independently from the entity of associated thyroid diseases and the results of the above imaging techniques, FNA-PTH resulted in the best diagnostic tool (100\% sensitivity and specificity) in the identification of all HP. As shown in Fig. 2, this excellent result was obtained with a rather arbitrary cutoff of $103 \mathrm{pg} / \mathrm{ml}$ corresponding to three times the highest FNA-PTH concentration $(34.3 \mathrm{pg} / \mathrm{ml})$ found in our series of notHP lesions. Indeed, FNA-PTH technique helped to identify the site of the neck harboring HP when preoperative localization studies (US and MIBI scan images) resulted negative or discordant (e.g. in presence of large NG and/or AIDT) and also allowed to select an adequate minimally invasive parathyroid surgical approach (e.g. unilateral neck exploration instead of BNE) in these cases. Finally, FNA cytology displayed low sensitivity both in group I and in group II patients $(56.2$ and $53.6 \%$ respectively) independently from the associated thyroid disorders. This phenomenon is in keeping with the known difficulties in distinguishing parathyroid from thyroid cells $(33,34)$. The different diagnostic accuracy between these FNA techniques is explained by the minimal amount of material needed to assay PTH-FNA, which was not sufficient for cytology.

The analysis of false-negative MIBI results of group II patients showed only in $2 / 14$ cases the presence of known interfering factors of MIBI uptake, such as small size and cystic degeneration of two PA (patients \#3 and \#4 of group II-A), while in the remaining 8/12 cases (66.7\%) a concomitant AITD (seven HT and one GD) was detected. It may be hypothesized that the inflammatory process related to AITD might be responsible for MIBI-negative scan by interferences on the mechanism of uptake, retention, and/or washout time of MIBI by parathyroid cells. To our knowledge, this is the first description of this association and further investigations are needed to better characterize the real prevalence of AITD in pHPT patients and clarify the potential interfering mechanism on MIBI function.

This study also confirms that MIBI false-positive scans (all detected in group II) were mainly caused by increased MIBI uptake of concomitant TNs. As previously reported (20), MIBI retention was observed in hypermetabolic oncocytic tumors (one oncocytic variant of TA and two oncocytic variants of PTC and FC) and TA (one hyperfunctioning adenoma and one classic variant), while the remaining five MIBI-positive scans were represented by three classic variants of PTC and two HTNs. Moreover, two other sources of MIBI false-positive uptake were represented by a recurrence of neck lymphoma and a mediastinum recurrence of lung neoplasia.

In our study, FNA was well tolerated, no complications and fibrosis were observed in any of the aspirated glands; no difficulties in operating setting and in distinguishing benign from malignant HP were reported when comparing this series with patients not submitted to this procedure (not reported in this paper). This good performance was obtained by adopting some technical precautions, as the use of small thin-bore needles (22-25 gauge) and a limited number (not more than one or two) of not-traumatic passes on all neck masses.

Accordingly, with Abraham et al. (38), FNA resulted in a safe technique when the above-described procedures were applied. However, it should be noted that in the presence of suspicious multiple parathyroid gland disease (or in patients with concomitant significant thyroid diseases), as well as in the presence of a truepositive result of PTH-FNA, other diagnostic imaging techniques (e.g. CT or magnetic resonance) may be proposed before a BNE in order to correctly find all HP and avoid recurrence or persistence of pHPT. We conclude that US-guided FNA-PTH should be used appropriately only in selected cases (i.e. when US and MIBI scan give conflicting results such as MIBI-negative cases, atypical location, multiple positive MIBI areas, as may happen in AITD/NG patients) and not applied routinely in pHPT. This technique helps the surgeon to perform a quicker operation with a higher degree of success and as an added benefit enables the identification of incidental thyroid tumors that coexist with pHPT (40) that can be effectively addressed during the same surgery.

\section{Declaration of interest}

The authors declare that there is no conflict of interest that could be perceived as prejudicing the impartiality of the research reported.

\section{Funding}

This research did not receive any specific grant from any funding agency in the public, commercial or not-for-profit sector.

\section{Acknowledgements}

Centro Studio per la Prevenzione e Terapia delle Malattie della Tiroide.

\section{References}

1 Brown EM. The pathophysiology of primary hyperparathyroidism. Journal of Bone and Mineral Research 200217 (Suppl 2) N24-N29. 
2 Marx SJ, Simonds WF, Agarwal SK, Burns AL, Weinstein LS, Cochran C, Skarulis MC, Spiegel AM, Libutti SK, Alexander HR Jr et al. Hyperparathyroidism in hereditary syndromes: special expressions and special managements. Journal of Bone and Mineral Research 200217 (Suppl 2) N37-N43.

3 Bilezikian JP, Potts JT Jr, Fuleihan Gel H, Kleerekoper M, Neer R, Peacock M, Rastad J, Silverberg SJ, Udelsman R \& Wells SA Jr. Summary statement from a workshop on asymptomatic primary hyperparathyroidism: a perspective for the 21st century. Journal of Bone and Mineral Research 200217 (Suppl 2) N2-N11.

4 Kearns AE \& Thompson GB. Medical and surgical management of hyperparathyroidism. Mayo Clinic Proceedings 200277 87-91. (doi:10.4065/77.1.87)

5 Udelsman R. Six hundred fifty-six consecutive explorations for primary hyperparathyroidism. Annals of Surgery 2002235 665-670 (discussion 670-672). (doi:10.1097/00000658-20020 5000-00008)

6 Siperstein A, Berber E, Mackey R, Alghoul M, Wagner K \& Milas M. Prospective evaluation of sestamibi scan, ultrasonography, and rapid PTH to predict the success of limited exploration for sporadic primary hyperparathyroidism. Surgery 2004136 872-880. (doi:10.1016/j.surg.2004.06.024)

7 Bergenfelz A, Lindblom P, Tibblin S \& Westerdahl J. Unilateral versus bilateral neck exploration for primary hyperparathyroidism: a prospective randomized controlled trial. Annals of Surgery 2002236 543-551. (doi:10.1097/00000658-20021100000001)

8 Henry JF, Iacobone M, Mirallie E, Deveze A \& Pili S. Indications and results of video-assisted parathyroidectomy by a lateral approach in patients with primary hyperparathyroidism. Surgery 2001130 999-1004. (doi:10.1067/msy.2001.119112)

9 Abraham D, Sharma PK, Bentz J, Gault PM, Neumayer L \& McClain DA. Utility of ultrasound-guided fine-needle aspiration of parathyroid adenomas for localization before minimally invasive parathyroidectomy. Endocrine Practice 200713 333-337.

10 Mitchell BK, Merrell RC \& Kinder BK. Localization studies in patients with hyperparathyroidism. Surgical Clinics of North America 199575 483-498.

11 Gofrit ON, Lebensart PD, Pikarsky A, Lackstein D, Gross DJ \& Shiloni E. High-resolution ultrasonography: highly sensitive, specific technique for preoperative localization of parathyroid adenoma in the absence of multinodular thyroid disease. World Journal of Surgery 199721 287-290 (discussion 290-291). (doi:10.1007/s002689900230)

12 Tziakouri C, Eracleous E, Skannavis S, Pierides A, Symeonides P \& Gourtsoyiannis N. Value of ultrasonography, CT and MR imaging in the diagnosis of primary hyperparathyroidism. Acta Radiologica 199637 720-726. (doi:10.3109/02841859609177706)

13 Johnston LB, Carroll MJ, Britton KE, Lowe DG, Shand W, Besser GM \& Grossman AB. The accuracy of parathyroid gland localization in primary hyperparathyroidism using sestamibi radionuclide imaging. Journal of Clinical Endocrinology and Metabolism 199681 346-352. (doi:10.1210/jc.81.1.346)

14 Haber RS, Kim CK \& Inabnet WB. Ultrasonography for preoperative localization of enlarged parathyroid glands in primary hyperparathyroidism: comparison with $(99 \mathrm{~m})$ technetium sestamibi scintigraphy. Clinical Endocrinology 200257 241-249. (doi:10.1046/j.1365-2265.2002.01583.x)

15 Hetrakul N, Civelek AC, Stagg CA \& Udelsman R. In vitro accumulation of technetium-99m-sestamibi in human parathyroid mitochondria. Surgery 2001130 1011-1018. (doi:10.1067/ msy.2001.118371)

16 Mehta NY, Ruda JM, Kapadia S, Boyer PJ, Hollenbeak CS \& Stack BC Jr. Relationship of technetium Tc 99m sestamibi scans to histopathological features of hyperfunctioning parathyroid tissue. Archives of Otolaryngology - Head \& Neck Surgery 2005 131 493-498. (doi:10.1001/archotol.131.6.493)

17 O'Doherty MJ, Kettle AG, Wells P, Collins RE \& Coakley AJ. Parathyroid imaging with technetium-99m-sestamibi: preoperative localization and tissue uptake studies. Journal of Nuclear Medicine 199233 313-318.
18 Pons F, Torregrosa JV \& Fuster D. Biological factors influencing parathyroid localization. Nuclear Medicine Communications 2003 24 121-124. (doi:10.1097/00006231-200302000-00003)

19 Kroemer G, Dallaporta B \& Resche-Rigon M. The mitochondrial death/life regulator in apoptosis and necrosis. Annual Review of Physiology 199860 619-642. (doi:10.1146/annurev.physiol.60. 1.619)

20 Boi F, Lai ML, Deias C, Piga M, Serra A, Uccheddu A, Faa G \& Mariotti S. The usefulness of $99 \mathrm{mTc}-S e s t a M I B I$ scan in the diagnostic evaluation of thyroid nodules with oncocytic cytology. European Journal of Endocrinology $2003 \quad \mathbf{1 4 9} 493-498$. (doi:10.1530/eje.0.1490493)

21 Fukumoto M. Single-photon agents for tumor imaging: 201Tl, 99mTc-MIBI, and 99mTc-tetrofosmin. Annals of Nuclear Medicine 200418 79-95. (doi:10.1007/BF02985098)

22 Chapuis Y, Fulla Y, Bonnichon P, Tarla E, Abboud B, Pitre J \& Richard B. Values of ultrasonography, sestamibi scintigraphy, and intraoperative measurement of 1-84 PTH for unilateral neck exploration of primary hyperparathyroidism. World Journal of Surgery 199620 835-839 (discussion 839-840). (doi:10.1007/ s002689900127)

23 Erbil Y, Barbaros U, Salmaslioglu A, Tunaci M, Ozbey N, Bozbora A \& Ozmarmagan S. Value of parathyroid hormone assay for preoperative sonographically guided parathyroid aspirates for minimally invasive parathyroidectomy. Journal of Clinical Ultrasound 200634 425-429. (doi:10.1002/jcu.20275)

24 Lumachi F, Marzola MC, Zucchetta P, Tregnaghi A, Cecchin D \& Bui F. Hyperfunctioning parathyroid tumours in patients with thyroid nodules. Sensitivity and positive predictive value of highresolution ultrasonography and $99 \mathrm{mTc}$-sestamibi scintigraphy. Endocrine-Related Cancer 200310 419-423. (doi:10.1677/erc.0. 0100419)

25 Mihai R, Gleeson F, Buley ID, Roskell DE \& Sadler GP. Negative imaging studies for primary hyperparathyroidism are unavoidable: correlation of sestamibi and high-resolution ultrasound scanning with histological analysis in 150 patients. World Journal of Surgery 200630 697-704. (doi:10.1007/s00268005-0338-9)

26 Boi F, Cau R, Piga M, Serra A, Loy M, Lai ML \& Mariotti S. 99mTcSestaMIBI scintigraphy of thyroid gland in a patient with primary hyperparathyroidism: unusual features due to coexistence of a thyroid papillary carcinoma. Clinical Endocrinology 200359 823-824. (doi:10.1046/j.1365-2265.2003.01937.x)

27 dell'Erba L, Baldari S, Borsato N, Bruno G, Calo-Gabrieli G, Carletto M, Ciampolillo A, Dondi M, Erba P, Gerundini P et al. Retrospective analysis of the association of nodular goiter with primary and secondary hyperparathyroidism. European Journal of Endocrinology 2001145 429-434. (doi:10.1530/eje.0.1450429)

28 Marcocci C, Mazzeo S, Bruno-Bossio G, Picone A, Vignali E, Ciampi M, Viacava P, Naccarato AG, Miccoli P, Iacconi P et al. Preoperative localization of suspicious parathyroid adenomas by assay of parathyroid hormone in needle aspirates. European Journal of Endocrinology 1998139 72-77. (doi:10.1530/eje.0. 1390072)

29 Doppman JL, Krudy AG, Marx SJ, Saxe A, Schneider P, Norton JA, Spiegel AM, Downs RW, Schaaf M, Brennan ME et al. Aspiration of enlarged parathyroid glands for parathyroid hormone assay. Radiology 1983148 31-35.

30 Barczynski M, Golkowski F, Konturek A, Buziak-Bereza M, Cichon S, Hubalewska-Dydejczyk A, Huszno B \& Szybinski Z. Technetium-99m-sestamibi subtraction scintigraphy vs. ultrasonography combined with a rapid parathyroid hormone assay in parathyroid aspirates in preoperative localization of parathyroid adenomas and in directing surgical approach. Clinical Endocrinology 200665 106-113. (doi:10.1111/j.1365-2265.2006. 02556.x)

31 Norman J, Politz D \& Browarsky I. Diagnostic aspiration of parathyroid adenomas causes severe fibrosis complicating surgery and final histologic diagnosis. Thyroid $2007 \mathbf{1 7}$ 1251-1255. (doi:10.1089/thy.2007.0081) 
32 Alwaheeb S, Rambaldini G, Boerner S, Coire C, Fiser J \& Asa SL. Worrisome histologic alterations following fine-needle aspiration of the parathyroid. Journal of Clinical Pathology 200659 1094-1096. (doi:10.1136/jcp.2005.029017)

33 Dimashkieh H \& Krishnamurthy S. Ultrasound guided fine needle aspiration biopsy of parathyroid gland and lesions. CytoJournal 20063 6. (doi:10.1186/1742-6413-3-6)

34 Agarwal AM, Bentz JS, Hungerford R \& Abraham D. Parathyroid fine-needle aspiration cytology in the evaluation of parathyroid adenoma: cytologic findings from 53 patients. Diagnostic Cytopathology 200937 407-410. (doi:10.1002/dc.21020)

35 Galen RS \& Gambino SR. How to determine the predictive value and efficiency of a test when reading a scientific paper. In: RS Galen, SR Gambino, eds. Beyond normality: the predictive value and efficiency of medical diagnoses, pp 29-40. New York: John Wiley, 1975.

36 Kao CH, Wang SJ, Liao SQ, Lin WY \& Hsu CY. Quick diagnosis of hyperthyroidism with semiquantitative 30-minute technetium99m-methoxy-isobutyl-isonitrile thyroid uptake. Journal of Nuclear Medicine 199334 71-74.

37 Erbil Y, Barbaros U, Yanik BT, Salmaslioglu A, Tunaci M, Adalet I, Bozbora A \& Ozarmagan S. Impact of gland morphology and concomitant thyroid nodules on preoperative localization of parathyroid adenomas. Laryngoscope 2006116 580-585. (doi:10.1097/01.MLG.0000203411.53666.AD)

38 Abraham D, Duick DS \& Baskin HJ. Appropriate administration of fine-needle aspiration (FNA) biopsy on selective parathyroid

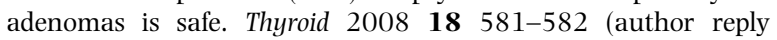
583-584). (doi:10.1089/thy.2007.0341)

39 Gomez-Ramirez J, Sancho-Insenser JJ, Pereira JA, Jimeno J, Munne A \& Sitges-Serra A. Impact of thyroid nodular disease on $99 \mathrm{mTc}$-sestamibi scintigraphy in patients with primary hyperparathyroidism. Langenbeck's Archives of Surgery 2010395 929-933. (doi:10.1007/s00423-010-0680-8)

40 Ogawa T, Kammori M, Tsuji E, Kanauchi H, Kurabayashi R, Terada K, Mimura Y \& Kaminishi M. Preoperative evaluation of thyroid pathology in patients with primary hyperparathyroidism. Thyroid 200717 59-62. (doi:10.1089/thy.2006.0182)

Received 23 August 2012

Revised version received 18 October 2012

Accepted 23 October 2012 